\title{
A post-COVID-19 model of tourism and hospitality workforce resilience
}

\author{
Antje Martins, Tyler Riordan \& Sara Dolnicar
}

The University of Queensland

COVID-19 is proving more disruptive to tourism and hospitality than World War II (Hunt, 2020). Workers in these industries are hardest hit (Remeikis, 2020) because few of them had continuous employment contracts before the pandemic, instead relying on non-standard and contingent arrangements including self-employment, subcontracting, and casual work. Nonstandard workers typically lack entitlements such as annual, sick and carers leave (Markey \& McIvor, 2018). Of all hospitality workers, 65\% are non-standard workers (Gilfillan, 2018). A $25 \%$ loading on hourly wages is designed to allow them to build a safety net (Gilfillan, 2018), but this loading is insufficient to ensure workers' livelihoods for an extended period of time without work (Campbell \& Burgess, 2018).

Non-standard work is becoming more common around the world, with workers engaged as necessary without a guarantee of ongoing employment (Markey \& McIvor, 2018). The relatively recent emergence of online on-demand (De Stefano, 2016) and peer-to-peer trading platforms (Dolnicar, 2019) provide additional non-standard working opportunities (Stewart \& Stanford, 2017). In hospitality and tourism, online platforms such as Uber Eats and Airbnb arrange such 'gigs'. Platform workers, as opposed to casual employees, are not employees and unable to access associated benefits or protections (Goods, Veen, \& Barratt, 2019).

The flexibility of non-standard forms of work minimizes risks for employers and can benefit some workers, especially those with competing engagements such as education or caring responsibilities (Markey \& McIvor, 2018), and those unable to secure permanent employment (Kaine \& Josserand, 2019). Non-standard work also offers an entry point into the local workforce for migrants (Duncan, Scott, \& Baum, 2013).

However, non-standard work is also associated with insecurity and income instability, which can negatively affect mental health and increase gaps within society (Robinson, Martins, Solnet, \& Baum, 2019). COVID-19 makes visible these disadvantages as non-standard workers struggle to support themselves during forced leave (Plastow, 2020), highlighting the need to rethink the long-term viability of existing forms of work in tourism and hospitality. This research note proposes a new post-COVID-19 model of tourism and hospitality workforce resilience.

The following key insights from the COVID19 pandemic inform the model:

(1) Non-standard work arrangements, even with a safety-net loading, do not offer sufficient protection in the case of a pandemic when workers earn no income for extended periods of time.

(2) Pandemics affect sectors differently. Non-essential services suffer most, while essential services experience increased demand. Workforce needs shift quickly and dramatically. During COVID-19, for example, supermarkets desperately needed additional workers, while other sectors went into hibernation.

(3) In pandemics, one of two characteristics are valued in workers: High-level narrow expertise in critical areas, like intensive care and vaccine development (Humphrey \& Nash, 2020); or transferrable skills facilitating worker mobility from hibernating to 
emergency sectors of the economy. During COVID-19, for example, tourism workers transferred to supermarkets (McIlvaine, 2020).

(4) Pandemics are expected to become more common in the future (World Economic Forum, 2019). Economic sectors need to be more resilient as they are rebuilt post-COVID19.

Our study contributes to knowledge by putting forward a post-COVID-19 model of tourism and hospitality workforce resilience. This model is based on the notion of skills transferability within and across service sectors (Baum, 2002; Riley, 2004). It offers employers increased levels of flexibility, ensures a higher level of income security for workers, and is more likely to cover demand in emergency areas during a pandemic. The practical value of our model lies in its contribution towards pandemic-proofing nations around the world.

At the heart of the new model (Figure 1) lies the understanding that the service industry includes many sectors that workers can move across (Baum, 2002; Riley, 2004). . A worker is considered sector-mobile if they have skill sets that transfer across sectors. The tourism and hospitality sectors, for example, require much of their workforce to have a high level of soft or interpersonal skills (Elshaer \& Marzouk, 2019). These skills rely on the emotional labour of workers, including: face-to-face contact with the public; and the ability to produce an emotional state in another person; thus requiring the control of emotional activities (Hochschild, 2012). These are complemented by other interpersonal skills such as communication, empathy, big-picture thinking, and the ability to find a common ground (Elshaer \& Marzouk, 2019). Such skills are just as important in call centres across a range of different sectors, as they are for supermarket workers; they are sector-transferable (Shaw, 1984).

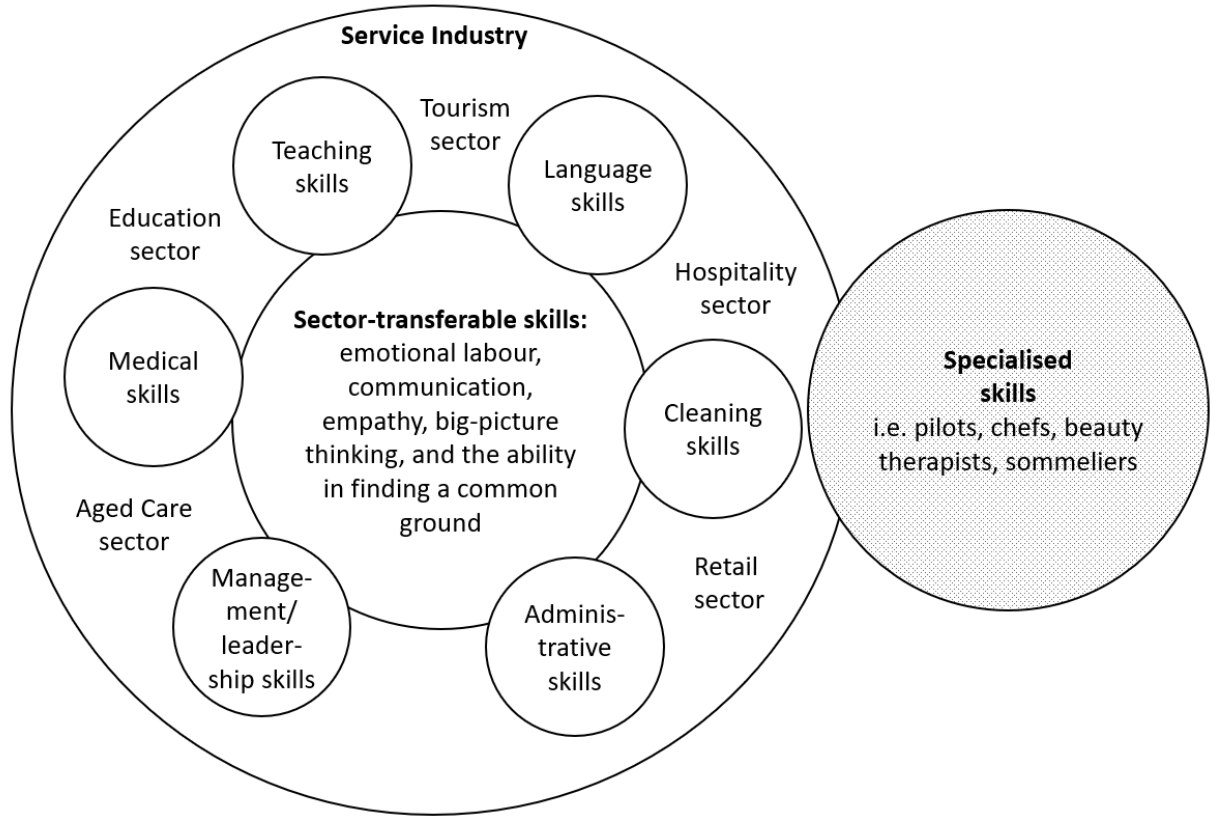

Figure 1: Sector-mobility based on sector-transferable skills vs specialised skills

In a sector-mobile world, transferable skills are increasingly valuable as they give workers the flexibility to move between different sectors following demand and capitalising on available opportunities. Sector-mobile workers also assist economies during downturns as 
they reduce unemployment and fill critical employment shortages. However, the transferability of skills is currently undervalued by employers, workers, and trainers alike (Snell, Gekara, \& Gatt, 2016).

Once a workforce entrant has acquired sector-transferable skills, they can work across all sectors within the service industry. Some sectors may require sector-specific skills such as foreign language abilities in tourism and hospitality. Some employers may also want to train their workers in role-specific skills. Each additional sector- and role-specific skill set of a worker further increases employment security for the individual and workforce resilience of the nation as a whole. For example, a worker may have sector-transferable skills, administrative skills, and basic medical training. Such a worker may have worked in hospitality originally, but in a pandemic, when hospitality is in hibernation, they can move to an aged care home, or assist in a call centre at a government welfare agency.

Whilst the notion of sector transferable skills (Shaw, 1984, Gekara \& Snell, 2018) and labour mobility (Riley, 2004) is not new, there is not enough attention being paid to its usefulness, especially during external shocks such as pandemics. While pandemics increase the need for sector-transferable skills and sector-mobile workers, there is still an acute need in such times for people who are highly trained experts in very specific fields, such as staff in intensive care units in hospitals and technicians able to manufacture medical equipment. But highly trained experts in other areas may face unemployment during the hibernation of their industries. With tourism and hospitality in hibernation during COVID-19, pilots, chefs, sommeliers and beauty therapists are unemployed (SBS News, 2020; Shine, 2020), and unlikely to find demand for their expertise in other industries. Many specialised skills may not be needed in times of a pandemic, limiting available employment alternatives. Focusing on sector-transferable skills is thus increasingly important if economic shocks, including pandemics, become more common in the future.

Both flexibility and income security matter to workers. The post-COVID-19 model of tourism and hospitality workforce resilience requires flexible and secure work arrangements. We propose that workers are no longer employed in specific sectors, but are instead considered service industry workers with sectors uniting to create a services industry community. Within this community, registered sector-mobile workers can move between employers and sectors based on demand. Contractually, there are different options. Workers could be engaged as contractors with the ability to frequently change workplace or sector when required. Whilst this provides flexibility and security due to the maximised employment options; entitlements, protections, and benefits are not ensured. Alternatively, workers could be employed by organisations and lent from low to high demand sector employers for a limited time against a fee. Such an arrangement opens up the possibility for continuous entitlements, protections and benefits. Another option would be for a central administering entity to employ all registered sector-mobile workers, which are then deployed to different employers. Again, this arrangement supports continuous entitlements, protections and benefits.

In terms of training for a post-COVID-19 model of tourism and hospitality workforce resilience, universities and registered training operators would need to provide generalised training in sector-transferable skills. Once graduated, service industry workers have their credentials recognised to enter any service sector. If additional training is required, workers can learn sector- and even role-specific skills. The more sector- and role-specific skills they acquire, the higher their value as a service worker because they can fill gaps across a range of service industry sectors. 
To conclude: The COVID-19 pandemic has demonstrated the vulnerability of tourism and hospitality workers in non-standard work arrangements, and offered an opportunity to redesign industries while rebuilding them. We propose a post-COVID-19 model of tourism and hospitality workforce resilience that prioritises diverse skills and flexibility, while providing more security for our highly skilled workforces.

Reconceptualising the service industry as a services industry community will allow workers with sector-transferable skills to move between service sectors to improve their employment opportunities and increase income security. Whilst sector- and role-specific training may still be required, the recognition of sector-transferable skills will ensure workers are sufficiently equipped to do their job. Our model also addresses the lack of awareness of the importance of skills transferability by employers, workers, and trainers (Snell et al., 2016), and adds to the discussion of resilient workforces. Workforce resilience is not only critically important in the context of pandemics and economic crises, but also contributes to addressing the increased use of technology and automation for service workforces moving forward.

\section{References}

Baum, T. (2002). Skills and training for the hospitality sector: a review of issues. Journal of vocational Education and Training, 54(3), 343-364.

Campbell, I., \& Burgess, J. (2018). Patchy progress? Two decades of research on precariousness and precarious work in Australia. Labour \& Industry: A Journal of the Social and Economic Relations of Work, 28(1), 48-67.

Dolnicar, S. (2019). A review of research into paid online peer-to-peer accommodation: Launching the Annals of Tourism Research curated collection on peer-to-peer accommodation. Annals of Tourism Research, 75, 248-264.

Duncan, T., Scott, D. G., \& Baum, T. (2013). The mobilities of hospitality work: An exploration of issues and debates. Annals of Tourism Research, 41, 1-19.

Elshaer, A. M., \& Marzouk, A. M. (2019). Labor in the tourism and hospitality industry: skills, ethics, issues, and rights. Boca Raton: CRC Press.Gekara, V., \& Snell, D. (2018). Designing and delivering skills transferability and employment mobility: the challenges of a market-driven vocational education and training system. Journal of Vocational Education \& Training, 70(1), 107-129.

Gilfillan, G. (2018). Characteristics and use of casual employees in Australia. Parliament of Australia, Research Paper Series, Canberra.

Goods, C., Veen, A., \& Barratt, T. (2019). “Is your gig any good?” Analysing job quality in the Australian platform-based food-delivery sector. Journal of Industrial Relations, $61(4), 502-527$.

Hochschild, A. R. (2012). The Managed Heart: commercialization of human feeling (3rd ed.). Berkeley: University of California Press.

Humphrey, T., \& Nash, D. (2020). UQ fast tracks nurses in response to COVID-19 pandemic. Retrieved April 16, 2020, from https:/www.uq.edu.au/news/article/2020/04/uq-fast-tracks-nurses-response-covid-19pandemic

Hunt, R. (2020). Marriott CEO: Coronavirus is hurting the hotel chain worse than 9/11 or World War II. Retrieved March 25, 2020, from 
https://www.nasdaq.com/articles/marriott-ceo\%3A-coronavirus-is-hurting-the-hotelchain-worse-than-9-11-or-world-war-ii-2020

Kaine, S., \& Josserand, E. (2019). The organisation and experience of work in the gig economy. Journal of Industrial Relations, 61(4), 479-501.

Markey, R., \& McIvor, J. (2018). Regulating casual employment in Australia. Journal of Industrial Relations, 60(5), 593-618.

McIlvaine, H. (2020). More hands on deck. Retrieved April 16, 2020, from https://insideretail.com.au/news/more-hands-on-deck-woolies-invites-ex-qantas-staff-toapply-for-jobs-202003

Plastow, K. (2020). Pretty screwed. Retrieved March 25, 2020, from https://thenewdaily.com.au/finance/finance-news/2020/03/11/coronavirus-casualworker-rent/

Remeikis, A. (2020). Australian government won't "jump to a solution" to help casual workers in coronavirus crisis. Retrieved March 25, 2020, from The Guardian website: https://www.theguardian.com/world/2020/mar/10/australian-government-warned-not-todrag-its-feet-on-help-for-casual-workers-in-coronavirus-crisis

Riley, M. (2004). Labor Mobility and Market Structure in Tourism. In A. A. Lew, C. M. Hall, A. M. Williams (Eds.), A Companion to Tourism (pp. 135-145). Oxford: Blackwell Publishing Ltd.

Robinson, R. N. S., Martins, A., Solnet, D. J., \& Baum, T. (2019). Sustaining precarity: critically examining tourism and employment. Journal of Sustainable Tourism, 27(7), 1008-1025.

SBS News. (2020). COVID-19: Airlines around the world slash schedules, jobs and pay. Retrieved March 25, 2020, from https://www.sbs.com.au/news/covid-19-airlinesaround-the-world-slash-schedules-jobs-and-payShaw, K. L. (1984). A formulation of the earnings function using the concept of occupational investment. Journal of Human Resources, 319-340.

Shine, R. (2020). Coronavirus pandemic leaves businesses struggling to survive the COVID19 shutdown. Retrieved April 14, 2020, from https://www.abc.net.au/news/2020-0404/coronavirus-shutdown-leaves-businesses-struggling-to-survive/12116334

Snell, D., Gekara, V., \& Gatt, K. (2016). Cross-occupational skill transferability: challenges and opportunities in a changing economy. Retrieved from https://www.ncver.edu.au/research-and-statistics/publications/all-publications/crossoccupational-skill-transferability-challenges-and-opportunities-in-a-changing-economy

Stewart, A., \& Stanford, J. (2017). Regulating work in the gig economy: What are the options? The Economic and Labour Relations Review, 28(3), 420-437.

World Economic Forum. (2019). Outbreak readiness and business impact protecting lives and livelihoods across the global economy. Retrieved April 24, 2020, from http://www3.weforum.org/docs/WEF HGHI_Outbreak_Readiness_Business_Impact.pdf 